\title{
Uso de sanitizantes na redução da carga microbiana de mandioca minimamente processada
}

\author{
Use of sanitizants on the reduce of microbial rate of cassava \\ minimally processed
}

\author{
Daniela Guerra Lund ${ }^{1}$ Lelis Aparecida Petrini ${ }^{2}$ \\ José Antonio Guimarães Aleixo ${ }^{3}$ Cesar Valmor Rombaldi ${ }^{2}$
}

\section{RESUMO}

Foi avaliado o efeito de dois sanitizantes clorados, em diferentes $\mathrm{pH}$, na redução da carga microbiana em mandioca minimamente processada. As raízes foram colhidas na zona rural da região de Pelotas-RS. Após a colheita foram selecionadas, lavadas, descascadas, cortadas em toletes e submetidas aos seguintes tratamentos: 1) sem lavagem; 2) lavagem em água destilada; 3) imersão em solução de dicloro s. triazinatriona sódica dihidratada (Sumaveg ${ }^{\circledR}$ ) a $100 \mathrm{mg} \mathrm{L}^{-1}$, por 10 minutos; 4) imersão em solução de dicloro s. triazinatriona sódica dihidratada a $200 \mathrm{mg} \mathrm{L}^{-1}$, por 10 minutos; 5) imersão em solução de hipoclorito de sódio a $100 \mathrm{mg} \mathrm{L} \mathrm{L}^{-1}$, por 15 minutos; 6) imersão em solução de hipoclorito de sódio a $200 \mathrm{mg} \mathrm{L}^{-1}$, por 15minutos; 7) imersão em solução de hipoclorito de sódio a $100 \mathrm{mg} \mathrm{L}^{-1}$, pH 6,0, durante $15 \mathrm{~min}$ e 8) imersão em solução de hipoclorito de sódio a $200 \mathrm{mg} \mathrm{L}^{-1}$, pH 6,0, durante $15 \mathrm{~min}$. As raízes foram analisadas antes e 15 min após a aplicação dos tratamentos. Determinou-se a contagem total de: mesófilos aeróbios, psicrotróficos, bactérias láticas, coliformes totais, coliformes fecais e mofos e leveduras. Nas soluções sanitizantes sem ajuste de $\mathrm{pH}$, a lavagem apenas em água, reduziu em 1 ciclo logaritmo as contagens de bactérias láticas. Porém, em soluções com pH 6,0, as contagens de mesófilos foram reduzidas em três ciclos logaritmos e em dois ciclos para microrganismos psicrotróficos, bactérias láticas e mofos e leveduras, eliminando coliformes totais e fecais após $15 \mathrm{~min}$ de contato com o sanitizante. O uso de hipoclorito de sódio, sem ajuste do $\mathrm{pH}$ reduziu a carga microbiana de coliformes totais e fecais. Quando se empregou o dicloro s. triazinatriona sódica dihidratada, os resultados foram semelhantes aos obtidos com hipoclorito de sódio sem ajuste de $\mathrm{pH}$. As maiores reduções da carga microbiana, com eliminação dos coliformes totais e fecais, foram obtidas quando se utilizou hipoclorito de sódio, a 100 ou $200 \mathrm{mg} \mathrm{L}$

\begin{abstract}
${ }^{1}$, com pH ajustado para 6,0 e tempo de exposição de 15 minutos.
\end{abstract}

Palavras-chave: alimentos minimamente processados, sanitizantes, segurança alimentar.

\section{ABSTRACT}

The effect of two chlorine sanitizants, at different $\mathrm{pH}$, in reducing microbial counts from cassava fresh-cut was evaluated. The roots were harvested in the rural zone of Pelotas-RS. After harvest, they were selected, washed and submited to the following treatments: 1) without washing; 2) washing with distiled water; 3) imersing in $100 \mathrm{mg} \mathrm{L}^{-1}$ dichlorine s. triazinatrione dihidrate during 10 minutes; 4) imersing in $200 \mathrm{mg} \mathrm{L}^{-1}$ dichlorine s. triazinatrione dihidrate during 10 minutes; 5) imersing in $100 \mathrm{mg} \mathrm{L}^{-1}$ sodium hipochloride during 15 minutes; 6) imersing in $200 \mathrm{mg} \mathrm{L}^{-1}$ sodium hipochloride during 15 minutes; 7) imersing in $100 \mathrm{mg}$ $L^{-1}$ sodium hipochloride $p H 6.0$ during 15 minutes; 8) imersing in $200 \mathrm{mg} \mathrm{L}^{-1}$ sodium hipochloride $\mathrm{pH} 6.0$ during 15 minutes. The roots were analysed before and 15 minutes after the treatments application. The following microbial counts were carried out: mesophilic, psicrotrophic, lactic, total coliforms, fecal coliforms and molds and yeasts. Among the treatments without adjustment of the $\mathrm{pH}$ of solution, the one that used washing with water reduced the lactic bacterias counts in 1 logaritmic cicle. However, the solutions with $\mathrm{pH}$ adjusted to 6.0 reduced the mesophilic counts in 3 logaritmic cicles and the psicrotrophic, lactic and molds and yeasts counts in 2 logaritmic cicle, with elimination of total and fecal coliforms after 15 minutes in sanitizant solution. The use of sodium hipochloride, without adjustment of the $\mathrm{pH}$ reduced the microbial counts of total and fecal coliforms. When it was employed dichlorine s. triazinatrione dihidrate (Sumaveg ${ }^{\circledR}$ ), the results were similar to those obtained with sodium

${ }^{1}$ Departamento de Ciência e Tecnologia Agroindustrial, Faculdade de Agronomia Eliseu Maciel, FAEM, Universidade Federal de Pelotas (UFPel), 96010-900, Pelotas, RS, Brasil. E-mail: dguerralund@yahoo.com.br. Autor para correspondência.

${ }^{2}$ Departamento de Ciência e Tecnologia Agroindustrial, Faculdade de Agronomia Eliseu Maciel, FAEM, UFPel, Pelotas, RS, Brasil. ${ }^{3}$ Departamento de Nutrição, Faculdade de Nutrição, UFPel, Pelotas, RS, Brasil. 
hipochloride without adjustment of the pH. The biggest redutions of microbial counts, with elimination of the total and fecal coliforms were obtained when it was used 100 or $200 \mathrm{mg} \mathrm{L} \mathrm{L}^{-1}$, sodium hipochloride with $\mathrm{pH}$ adjusted to 6,0 and exposition time of 15 minutes.

Key words: minimally processed foods, sanitizants, food safety.

\section{INTRODUÇÃO}

Embora se trate de um típico produto brasileiro, apreciado pelo consumidor, nas mais variadas formas de preparo, o consumo per capita de mandioca ainda é considerado baixo, menor do que 1 kg.hab ${ }^{-1}$.ano (CEREDA, 2000). Dentre as principais causas do baixo consumo, destacam-se a sazonalidade e a pouca praticidade no preparo do produto, na forma como é oferecido no mercado.

A produção de mandioca minimante processada (MMP) tem sido proposta como alternativa para promover a ampliação do período de oferta e disponibilizar um alimento mais prático, ou seja, descascado, limpo e higienizado, pronto para ser utilizado (MIRANDA, 2000; CEREDA, 2000; OLIVEIRA et al., 2003).

As principais operações unitárias na produção de MMP são a seleção, lavagem, corte, descascamento, lavagem, sanitização, centrifugação, embalagem e refrigeração ou congelamento (CANTWELL, 1992; OLIVEIRA et al., 2003). Um dos problemas significativos detectados em MMP comercializada no mercado da Região Sul do estado do Rio Grande do Sul é a elevada carga microbiana presente no produto. LUND et al. (2004), analisando produtos de MMP, detectaram contagens de mesófilos

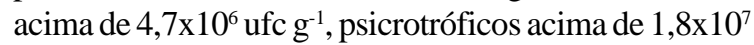
ufc g-1 ${ }^{-1}$ bactérias láticas acima de $2,8 \times 10^{7}$ ufc g-1 $^{-1}$, além de terem sido detectados coliformes totais e fecais. A presença de uma elevada carga microbiana em mandioca é normal, considerando-se que se tratam de raízes e o solo é fonte da maioria dos microrganismos de importância agroalimentar (VANETTI, 2000). Porém, durante o processamento, devem ser adotadas medidas preventivas que reduzam a contaminação e eliminem os microrganismos potencialmente causadores de toxinfecções alimentares (VANETTI, 2000).

Embora o emprego de ozônio, peróxido de hidrogênio e ácido peroxiacético venha sendo testado em alimentos minimamente processados, o uso de produtos à base de cloro ainda é majoritário (SANT’ANA et al., 2002). Além da importância da escolha do sanitizante mais adequado para determinado alimento, vários autores citam que o controle do pH na solução de sanitização é fundamental para a eficiência da operação (HURST, 1995, VANETTI, 2000, OLIVEIRA et al., 2003).

De maneira geral, para sanitização de frutas e hortaliças frescas são recomendadas concentrações de cloro livre entre 50 e $200 \mathrm{mg} \mathrm{L}^{-1}$, pH entre 5 e 7 , durante 3 a 20 minutos de exposição do produto ao sanitizante (VANETTI, 2000; OLIVEIRA et al., 2003).

O teor de cloro livre compreende as formas $\mathrm{Cl}_{2}$, ácido hipocloroso (HOCl) e o íon hipoclorito $\left(\mathrm{OCl}^{-1}\right)$. DELAQUIS et al. (2004) citam que o pH da solução deve ser mantido entre 6,0 e 7,5 para uma sanitização mais eficiente. Porém, nos produtos de MMP, têm-se detectado elevada carga de microrganismos indicadores de más condições higiênicas (coliformes totais e fecais). Duas hipóteses podem explicar esse fato: 1) as condições de sanitização e seu monitoramento não estão sendo suficientes para reduzir a carga microbiana; ou, 2) está havendo recontaminação do produto após a sanitização.

O objetivo deste trabalho foi avaliar o efeito de dois sanitizantes clorados, em diferentes $\mathrm{pH}$, na redução da carga microbiana em mandioca minimamente processada.

\section{MATERIAL E MÉTODOS}

As raízes de mandioca foram colhidas no município de Pelotas, RS, e transportadas em veículo não climatizado até o Laboratório de Processamento da Faculdade de Agronomia Eliseu Maciel. Após a recepção, as raízes foram lavadas em água, selecionadas, eliminando-se aquelas que apresentavam podridões, descascadas e cortadas transversalmente em toletes de aproximadamente $5 \mathrm{~cm}$ de comprimento, removendo-se os filamentos fibrosos.

Realizadas essas etapas, os toletes foram submetidos aos seguintes tratamentos: 1) sem lavagem; 2) lavagem em água destilada; 3) imersão em solução de dicloro s. triazinatriona sódica dihidratada (Sumaveg ${ }^{\circledR}$ ) a 100 $\mathrm{mg} \mathrm{L}^{-1}$, durante 10min; 4) imersão em solução de dicloro s. triazinatriona sódica dihidratada (Sumaveg ${ }^{\circledR}$ ) a 200 $\mathrm{mg} \mathrm{L}^{-1}$, durante 10min; 5) imersão em solução de hipoclorito de sódio a $100 \mathrm{mg} \mathrm{L}^{-1}$, durante 15min; 6) imersão em solução de hipoclorito de sódio a $200 \mathrm{mg} \mathrm{L}^{-1}$, durante $15 \mathrm{~min}$; 7) imersão em solução de hipoclorito de sódio a 100 $\mathrm{mg} \mathrm{L}^{-1}, \mathrm{pH} 6,0$, durante 15min e 8) imersão em solução de hipoclorito de sódio a 200 $\mathrm{mg} \mathrm{L}^{-1}$, pH 6,0, durante 15min.

$\mathrm{O}$ ajuste do $\mathrm{pH}$, naqueles tratamentos em que o procedimento foi adotado, foi feito adicionandose ácido cítrico à solução. O efeito dos tratamentos foi 
avaliado através de análises microbiológicas realizadas antes e depois da sanitização. Para comprovar que não houve recontaminação com a lavagem em água destilada, foi realizada análise microbiológica dessa água.

As avaliações microbiológicas realizadas foram as seguintes: contagem de bactérias mesófilas aeróbias, psicrotróficas, bactérias láticas, coliformes totais e fecais, mofos e leveduras. Os procedimentos adotados para as análises basearam-se nas recomendações do Bacteriological Analytical Manual (FDA, 1998). Para bactérias mesófilas, o meio utilizado foi ágar para contagem em placas (PCA, Merck, Darmstadt, Germany). Foi inoculado 1,0mL de diferentes diluições das amostras pela técnica "pourplate” e as placas de Petri foram incubadas a $37^{\circ} \mathrm{C}$ por 48h. Para contagem de bactérias psicrotróficas, também utilizou-se ágar para contagem em placas (PCA, Merck, Darmstadt, Germany). Neste caso, inoculou-se 0,1mL de diferentes diluições das amostras na superfície do meio de cultura e as placas de Petri foram incubadas a $7^{\circ} \mathrm{C}$ por 10 dias. Para bactérias láticas, o meio utilizado foi ágar para contagem em placas (PCA, Merck, Darmstadt, Germany) com bromocresol púrpura (0,03g $\left.\mathrm{L}^{-1}\right)$. Foi inoculado $1,0 \mathrm{~mL}$ de diferentes diluições das amostras pela técnica "pour-plate” e as placas de Petri foram incubadas a $30^{\circ} \mathrm{C}$ por $48 \mathrm{~h}$. Para mofos e leveduras, foi utilizado o meio ágar batata dextrosado acidificado (BDA, Merck, Darmstadt, Germany). Inoculou-se $1,0 \mathrm{~mL}$ de diferentes diluições das amostras pela técnica “pour-plate”, sendo a incubação realizada a $30^{\circ} \mathrm{C}$, durante quatro dias.

O delineamento experimental foi inteiramente casualizado, com três repetições, contendo oito tratamentos na tabela 1 e 2 tratamentos na tabela 2. As médias foram comparadas pelos testes de Tukey e " $\mathrm{t}$ " de student, ao nível de 5\% de probabilidade. Antes de serem submetidos à análise da variância, foi realizada a transformação logarítmica dos dados.

\section{RESULTADOS E DISCUSSÃO}

Foram verificadas elevadas contagens microbianas para psicrotróficos, bactérias láticas, mofos e leveduras, além de coliformes totais e fecais, que são microrganismos indicadores de más condições higiênicas, fato este que pode ser explicado em virtude da não realização do processo de lavagem e sanitização nos toletes de mandioca descascados (Tabela 1). Esse fato é normal, tendo-se em vista que a matéria-prima é retirada do solo, que é uma fonte rica em microrganismos. Observou-se ainda que somente para as bactérias lácticas, verificou-se a existência de diferença significativa ( $\alpha=5 \%)$ entre os tratamentos sem lavagem e com lavagem.

A realização da lavagem contribuiu não só para a remoção de sujidades mas também para a redução de microrganismos provenientes do solo o qual se encontrava aderido às raízes de mandioca após sua colheita, logo, com a lavagem das raízes efetuouse uma remoção parcial do solo aderido, e em virtude disto, obteve-se uma diminuição da carga microbiana nessas raízes, principalmente para psicrotróficos e bactérias láticas, além de coliformes totais e fecais, enfatizando o efeito do processo de sanitização e, conseqüentemente, ocasionado um aumento nos coeficientes de variação. Observou-se uma redução em média de 1 ciclo logarítmico para bactérias láticas, justificando assim, a existência de um coeficiente de variação de (CV=16,4\%) (Tabela 1). Verificou-se ainda, a existência de diferença significativa entre os sanitizantes na redução dos coliformes fecais, nos quais o hipoclorito de sódio mostrou-se mais eficiente, destacando assim seu efeito como sanitizante. Para as demais categorias microbianas, não houve diferença significativa ( $\alpha=5 \%$ ), enfatizando os resultados obtidos por (BERBARI et al., 2001; OLIVEIRA et al., 2003), os quais também verificaram esse comportamento.

Nos tratamentos em que se ajustou o $\mathrm{pH}$, a redução da carga microbiana foi significativa ( $\alpha=5 \%)$, em média, três ciclos logarítmicos para mesófilos, dois ciclos para psicrotróficos, bactérias láticas e mofos e leveduras, e eliminação dos coliformes totais e fecais. Conforme VANETTI (2000), este fato pode ser atribuído ao efeito do cloro como germicida de amplo espectro de ação, em virtude da reação com as proteínas da membrana das células microbianas interferindo no transporte de nutrientes e promovendo a perda de componentes celulares. Na tabela 2, observou-se o efeito do tempo de imersão para o sanitizante hipoclorito de sódio nas concentrações 100 e 200mg L-1 com ácido cítrico, através da análise estatística mediante a aplicação do teste "t", constatando-se que para mesófilos aeróbios, psicrotróficos, bactérias láticas, mofos e leveduras, coliformes totais e fecais o tempo de permanência dos toletes em ambas as concentrações exerceu influência significativa na redução microbiana. Verificou-se ainda que o ácido cítrico mostrou-se eficiente na redução dos coliformes totais. O conjunto de resultados obtidos indica que a mandioca é uma matéria-prima com elevada carga microbiana, com risco significativo de perigos de origem microbiológica, demonstrado pela presença de coliformes totais e fecais. Isso também foi relatado por OLIVEIRA et al. (2003), que detectaram 
Tabela 1 - Carga microbiana em mandioca minimamente processada influenciada pelo uso de diferentes agentes sanitizantes. Valores médios de 3 repetições

\begin{tabular}{|c|c|c|c|c|c|c|c|c|c|}
\hline Tratamentos & $\begin{array}{l}\text { pH antes da } \\
\text { imersão do } \\
\text { produto }\end{array}$ & $\begin{array}{c}\text { pH após } \\
\text { imersão } \\
\text { do produto }\end{array}$ & $\begin{array}{l}\text { Tempo após } \\
\text { imersão } \\
\text { (minutos) }\end{array}$ & $\begin{array}{l}\text { Mesófilos } \\
\text { Log } \\
\left(\mathrm{UFC} \mathrm{g}^{-1}\right)\end{array}$ & $\begin{array}{c}\text { Psicrotróficos } \\
\text { Log } \\
\left(\mathrm{UFC} \mathrm{g}^{-1}\right)\end{array}$ & $\begin{array}{l}\text { Láticas } \\
\text { Log } \\
\left(\mathrm{UFC} \mathrm{g}^{-1}\right)\end{array}$ & $\begin{array}{l}\text { Coliformes } \\
\text { totais } \\
\text { Log } \\
\left(\mathrm{NMP} \mathrm{g}^{-1}\right)\end{array}$ & $\begin{array}{l}\text { Coliformes } \\
\text { fecais } \\
\text { Log } \\
\left(\mathrm{NMP} \mathrm{g}^{-1}\right)\end{array}$ & 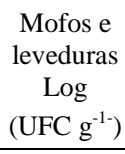 \\
\hline Sem lavagem & & & & $\begin{array}{c}3,23 \mathrm{a}^{*} \\
3,11 \mathrm{a}\end{array}$ & $\begin{array}{l}2,14 \mathrm{a} \\
2,65 \mathrm{a}\end{array}$ & $\begin{array}{l}3,32 \mathrm{a} \\
3,14 \mathrm{a}\end{array}$ & $\begin{array}{l}1,44 \mathrm{a} \\
1,75 \mathrm{a}\end{array}$ & $\begin{array}{l}1,32 \mathrm{a} \\
1,52 \mathrm{a}\end{array}$ & $\begin{array}{l}2,18 \mathrm{a} \\
2,40 \mathrm{a}\end{array}$ \\
\hline Com lavagem & $\begin{array}{l}7,9 \\
7,2\end{array}$ & $\begin{array}{l}7,0 \\
6,5\end{array}$ & & $\begin{array}{l}3,44 \mathrm{a} \\
3,32 \mathrm{a}\end{array}$ & $\begin{array}{l}2,23 \mathrm{a} \\
2,32 \mathrm{a}\end{array}$ & $\begin{array}{l}2,80 b \\
2,45 b\end{array}$ & $\begin{array}{l}1,58 \mathrm{a} \\
1,50 \mathrm{a}\end{array}$ & $\begin{array}{l}1,68 \mathrm{a} \\
1,23 \mathrm{a}\end{array}$ & $\begin{array}{l}2,51 \mathrm{a} \\
2,04 \mathrm{a}\end{array}$ \\
\hline $\mathrm{S}^{*} 100 \mathrm{mg} \mathrm{L} \mathrm{L}^{-1}$ & 6,0 & 6,0 & 10 & 3,30 a & $2,11 \mathrm{a}$ & $2,21 \mathrm{~b}$ & $1,79 \mathrm{a}$ & $1,12 \mathrm{a}$ & $2,38 \mathrm{a}$ \\
\hline $\mathrm{S} 200 \mathrm{mg} \mathrm{L} \mathrm{L}^{-1}$ & 6,0 & 6,0 & 10 & 3,32 a & $2,44 \mathrm{a}$ & $2,04 b$ & $1,34 \mathrm{a}$ & $1,38 \mathrm{a}$ & $2,23 \mathrm{a}$ \\
\hline HS $100 \mathrm{mg} \mathrm{L}^{-1}$ & 10,1 & 10,0 & 15 & 3,23 a & $2,51 \mathrm{a}$ & $2,62 \mathrm{~b}$ & $0,71 \mathrm{~b}$ & $0,70 \mathrm{~b}$ & $2,04 \mathrm{a}$ \\
\hline HS $200 \mathrm{mg} \mathrm{L}^{-1}$ & 10,5 & 10,6 & 15 & 3,19 a & $2,23 \mathrm{a}$ & $2,55 b$ & $1,23 \mathrm{a}$ & $0,98 \mathrm{~b}$ & $2,09 \mathrm{a}$ \\
\hline $\begin{array}{l}\text { Média geral } \\
\text { CV(\%) }\end{array}$ & & & & $\begin{array}{l}3,26 \\
3,05\end{array}$ & $\begin{array}{l}2,32 \\
8,13\end{array}$ & $\begin{array}{c}2,64 \\
16,48\end{array}$ & $\begin{array}{c}1.41 \\
24,21\end{array}$ & $\begin{array}{l}1,24 \\
24,5\end{array}$ & $\begin{array}{l}2,23 \\
8,00\end{array}$ \\
\hline
\end{tabular}

* Letras minúsculas diferentes, na vertical, diferem entre si pelo teste de Tukey a 5\% de probabilidade de erro

(• ) S= Sumaveg® dicloro s. triazinatriona sódica dihidratada; HS= hipoclorito de sódio

Tabela 2 - Carga microbiana em mandioca minimamente processada sob influência do pH da solução de hipoclorito de sódio. Valores médios de 3 repetições

\begin{tabular}{|c|c|c|c|c|c|c|c|c|c|}
\hline Tratamentos & $\begin{array}{c}\mathrm{pH} \text { antes da } \\
\text { imersão do } \\
\text { produto }\end{array}$ & $\begin{array}{l}\text { pH após } \\
\text { imersão } \\
\text { do } \\
\text { produto }\end{array}$ & Tempo & $\begin{array}{l}\text { Mesófilos } \\
\text { Log } \\
\left(\mathrm{UFC} \mathrm{g}^{-1}\right)\end{array}$ & $\begin{array}{c}\text { Psicrotróficos } \\
\text { Log } \\
\left(\mathrm{UFC} \mathrm{g}^{-1}\right)\end{array}$ & $\begin{array}{l}\text { Láticas Log } \\
\left(\mathrm{UFC} \mathrm{g}^{-1}\right)\end{array}$ & $\begin{array}{l}\text { Coliformes } \\
\text { totais } \\
\text { Log } \\
\left(\mathrm{NMP} \mathrm{g}^{-1}\right)\end{array}$ & $\begin{array}{l}\text { Coliformes fecais } \\
\text { Log } \\
\left(\mathrm{NMP} \mathrm{g}^{-1}\right)\end{array}$ & $\begin{array}{c}\text { Mofos e leveduras } \\
\log \\
\left(\mathrm{UFC} \mathrm{g}^{-1}\right)\end{array}$ \\
\hline $\begin{array}{l}\text { HS } 100 \mathrm{mg} \mathrm{L}^{-1} \\
+ \text { Ác.Cítrico }\end{array}$ & 6,0 & 6,0 & $\begin{array}{c}0 \\
15 \mathrm{~min}\end{array}$ & $\begin{array}{c}4,34 \mathrm{a}^{*} \\
1,07 \mathrm{~b}\end{array}$ & $\begin{array}{l}2,84 \mathrm{a} \\
1,69 \mathrm{~b}\end{array}$ & $\begin{array}{l}3,32 \mathrm{a} \\
1,30 \mathrm{~b}\end{array}$ & $\begin{array}{l}1,84 \mathrm{a} \\
0,47 \mathrm{~b}\end{array}$ & $\begin{array}{l}1,30 \mathrm{a} \\
0,47 \mathrm{~b}\end{array}$ & $\begin{array}{l}3,77 \mathrm{a} \\
1,30 \mathrm{~b}\end{array}$ \\
\hline $\begin{array}{l}\text { HS } 200 \mathrm{mg} \mathrm{L}^{-1} \\
+ \text { Ác.Cítrico }\end{array}$ & 6,0 & 6,0 & $\begin{array}{c}0 \\
15 \text { min }\end{array}$ & $\begin{array}{l}5,41 \mathrm{a} \\
2,14 \mathrm{~b}\end{array}$ & $\begin{array}{l}3,30 \mathrm{a} \\
1,90 \mathrm{~b}\end{array}$ & $\begin{array}{l}3,25 \mathrm{a} \\
1,30 \mathrm{~b}\end{array}$ & $\begin{array}{l}1,69 \mathrm{a} \\
0,47 \mathrm{~b}\end{array}$ & $\begin{array}{l}1,47 \mathrm{a} \\
0,47 \mathrm{~b}\end{array}$ & $\begin{array}{l}4,69 \mathrm{a} \\
2,47 \mathrm{~b}\end{array}$ \\
\hline
\end{tabular}

* Letras minúsculas diferentes, na vertical, diferem entre si pelo teste “t” a 5\% de probabilidade de erro

(• ) HS= hipoclorito de sódio

a presença de coliformes totais e fecais em raízes de mandioca, e por LUND et al. (2004), em MMP.

A desinfecção de toletes de mandioca em água sanitária 200ppm de cloro ativo, por 15 minutos, $\mathrm{pH}$ 6,0, manteve a qualidade visual do produto após armazenamento a $4^{\circ} \mathrm{C}$, durante 4 semanas OLIVEIRA et al (2003). A carga microbiana também foi reduzida de $10^{7} \mathrm{UFC} \mathrm{g}^{-1}$ (controle) para $10^{3} \mathrm{UFC} \mathrm{g}^{-1}$ após quatro semanas. Já para mofos e leveduras todas as amostras apresentaram contagens $<10$ e para coliformes totais e fecais todas as amostras apresentaram contagens $<2$. $\mathrm{O}$ ajuste do $\mathrm{pH}$, a temperatura, a concentração e o tempo de exposição do produto ao sanitizante influenciaram na eficiência da sanitização.

\section{CONCLUSÃO}

O agente sanitizante dicloro s. triazinatriona sódica dihidratada, nas concentrações de 100 e 200mg

Ciência Rural, v.35, n.6, nov-dez, 2005. 
$\mathrm{L}^{-1}$, mesmo a $\mathrm{pH}$ 6,0 e tempo de exposição de 10 minutos, não foi suficiente para reduzir a carga microbiana em mandioca minimamente processada. $\mathrm{O}$ ajuste do $\mathrm{pH}$ da solução de hipoclorito de sódio é determinante para eficiência da sanitização.

\section{REFERÊNCIAS}

BERBARI, S.A.G. et al. Efeito do cloro na água de lavagem para desinfecção de alface minimamente processada. Ciência e Tecnologia de Alimentos, v.21, p.197-201, 2001.

CANTWELL, M. Postharvest handling systems: minimally processed fruits and vegetables. In: KADER, A.A. (Ed). Postharvest technology of horticultural crops. 2. Daves: Univ. California, Division of horticulture and natural resources, 1992. p.277-281.

CEREDA, M.P. Desafios do processamento de mandioca. In: ENCONTRO NACIONAL SOBRE PROCESSAMENTO MÍNIMO DE FRUTAS E HORTALIÇAS, 2., 2000, Viçosa. Palestras... Viçosa: UFV, 2000. p.140-146.

DELAQUIS, P.J. et al. Implications of wash water chlorination and temperature for the microbiological and sensory properties of fresh-cut iceberg lettuce. Postharvest Biology and Technology, v.31, p.81-91, 2004.
FDA, Bacteriological analytical manual. 8.ed. Naryland: College Park, 1998. 581p.

HURST, W.C. Sanitation of lightly processed fruits and vegetables. HortScience, v.30, p.22-24, 1995.

LUND, D.G. et al. Qualidade microbiológica de mandioca minimamente processada. Sociedade Brasileira de Ciência e Tecnologia de Alimentos, 2004. No prelo.

MIRANDA, L.A. Características tecnológicas, agronômicas e de qualidade de mandioca de mesa. 2000. 93f. Tese (Doutorado em Ciência de Alimentos) - Curso de Pós-graduação em Ciência de Alimentos, Universidade Estadual de Londrina.

OLIVEIRA, M.A. de et al. Efeito da sanitização e de agente antioxidante em raízes de mandioca minimamente processadas. Brazilian Journal of Food Technology, v.6, p.339-344, 2003.

SANT'ANA, A. et al. Análise de perigos no processamento mínimo de vegetais. Higiene Alimentar, v.16, p.80-84, 2002.

VANETTI, M.C.D. Controle microbiológico e higiene no processamento mínimo. In: ENCONTRO NACIONAL SOBRE PROCESSAMENTO MÍNIMO DE FRUTAS E HORTALIÇAS, 2., 2000, Viçosa. Palestras... Viçosa: UFV, 2000. p.44-52. 